have appeared before are derived. The familiar figure in Denham and Clapperton's work of a mail-clad warrior and horse of Bornu is copied without any kind of acknowledgment. Very slight differences have been made in the present figure : thus in it the great toe only is placed in the stimup instead of the whole foot, as in the original, and thethe ear-blade is double instead of single, whilst the helmet has a plume added, but all the rest is directly copied without any reason being given for the alterations. A most remarkable defect in the book, considering that it is German and scientific, is the almost entire absence of references to former works of all kinds. As far as we have been able to discover there are only two references to ather books in the entire work, one to Fournel's "Les Berbes," the other to the publications of the German Geographical Society. Though Barth and Duveyrier are mentioned and their views are quoted, no references to their writings are given. And Denham and Clapperton are entirely ignored even in the account of Bornu. A serious drawback is that the book is published so long after the travels to which it 1elates were completed. We hope that the second volume may not be long in appearing. We understand that the book is shortly to be published in English. It is full of interesting and valuable matter and of scientific details.

\section{THE SCIENCE OF AGRICULTURE}

First Lessons in the Science of Agriculture; for Use in Indian Elementary Schools or Classes. Pp. 67. By J. B. Fuller. (Calcutta : Stanhope Press, I 879.)

THIS little primer is issued under the authority of the Department of Agriculture and Commerce, NorthWest Provinces and Oudh. If its teachings be accepted and followed by those for whom they are intended, increased and improved crops must be the consequence. Of course, within the narrow limits of some seventy small pages, we cannot expect to find the scientific basis of the art of agriculture fully developed; indeed, the explanations of the materials and processes with which Indian farming is concerned are neither numerous nor full. But to show clearly a few of the worst mistakes made by Eastern cultivators of the soil, and to indicate remedies and improved methods of procedure in but half-a-dozen cases, is a useful beginning of an important work. We note, in passing, a few examples of the recommendations, based upon scientific knowledge, which Mr. Fuller makes in these "First Lessons." On p. 7 the usefulness of a good tilth and of a feeding-ground deepened by thorough ploughing for crops during seasons of drought, is illustrated and enforced. We learn from pp. 26 and 27 that due importance is not generally attached to the selection and securing of the best varieties and qualities of seed for sowing the fields. Too often they sow any seed they have by them, the produce of their own fields, and often of inferior quality. Good kinds of grain, \&c., are thus found to be confined to one village, though they might be grown successfully in many neighbouring places. Thus, the village of Jaláli in the Aligarh district is well known for its fine white wheat; Sankni, in Bulandshahar, for its safflower; some districts north-west of Allahabad for indigo, and Hinganghát for cotton. The value of new plants to India is discussed on pp. $3 \mathrm{I}$ and 32 , the cases cited being tea, the potato, reana, and Egyptian cotton. Passing over a chapter in which some elementary facts about plant-food are given, we find many useful remarks (pp. 37 to 44) on the fertility of the soil and the means of restoring or increasing it. Here we are introduced to reh and usar. The former term is applied to the saline efflorescence, which, in some seasons especially, appear in many tracts of land in the North-West Provinces and elsewhere in India. Reh consists mainly of sodium and calcium sulphates, with some common salt and nitrates. The usar plain is infected with reh, but I cannot agree with Mr. Fuller in condemning the usar soils as sterile through deficiency of plant-food (p. 38). My analyses of such soils gave in most cases no evidence of deficiencies in the mineral elements of plant-nutrition, they merely showed an excess of soluble salts. What Mr. Fuller says about the best way of getting rid of reh is very judicious, so are his remarks about the sad waste of animal and vegetable residues (including indigo waste, and the bones of bullocks and buffaloes, in India) - residues which, instead of being burnt or neglected, should certainly be much more largely than at present ploughed into the land. His contrast between the work of the Indian plough and the English, the latter doing in one ploughing what the former needs twelve ploughings to accomplish, should be of some real service, especially as the new English-pattern ploughs made at Cawnpore are very light, and do not cost more than eight rupees apiece. By the use of this improved implement the "pan," which has been formed two or three inches under so large a tract of Indian soil by the rubbing of the old ploughshares and the trampling of the bullocks, would be broken up, and the rains would penetrate and moisten a much greater depth of soil. Mr. Fuller illustrates the advantage of increasing by such deep ploughing the depth of water-holding soil. He says : "In Madras, in the year 1878 , when there was a great famine from the failure of the rains, some land was ploughed with the European plough, and some with the native plough, on the Government farm. Neither was irrigated, and both had to depend for their water on the little rain that fell. The European-ploughed land gave a rice-crop of six maunds per acre; the native-ploughed land did not yield a single grain." The two last lessons in this useful little book contain some quite satisfactory explanations as to the respective merits of canal and well water, and of thin and thick seeding in India.

A. H. C.

\section{OUR BOOK SHELF}

On the Crystallography of Calcite. By J. R. McD. Irby, B.Sc., of Lynchburg, U.S. (Bonn: Charles Georgi, I878.)

ONE is pleased to find that, in an essay on the crystallography of calcite, by a gentleman who has received his training in America and Germany, the system of representation used by Prof. Miller has been adopted, and not the objectional modification employed by Professors Groth and Dana, jun. One regrets that the paper is unaccompanied by a stereographic projection, which would have much simplified the discussion of the distribution and position of the forms.

The original part of the essay consists of a criticism 